\title{
PERANCANGAN PERANGKAT LUNAK BANTU PEMBELAJARAN MATA KULIAH PERANGKAT KERAS BERBASIS PHP
}

\author{
Cita St. Munthakhabah. $\mathbf{R}^{1^{*}}$, Febriyani Syafri ${ }^{2}$ \\ ISTMIK Hasan Sulur Wonomulyo \\ 2SMP Negeri 5 Duampanua \\ *Email: citajanuari18@gmail.com
}

\begin{abstract}
This research is a software development research that aims to develop learning aids software for hardware subjects based on PHP (Perl Hypertext Preprocessor) in the Computer and Informatics Engineering Study Program, Department of Electrical Engineering Education, Faculty of Engineering, Makassar University. The design of instructional media is carried out by collecting learning materials then designing the software and the necessary database. The learning media that has been created are then validated by two media experts. The objects in this study were 37 students of class 04 class 2012 Informatics and Computer Engineering Education Department of Electrical Engineering Education Faculty of Engineering, Makassar State University, as many as 37 people who program hardware courses in the even semester of the 2012-2013 academic year. Data collection was carried out using a questionnaire given to respondents. The results of the descriptive analysis show that the views of PTIK JPTE FT UNM students on the implementation of PHP learning media in the Hardware course are in the good category or equal to $91.89 \%$.
\end{abstract}

Keywords: perl hypertext preprocessor, learning media, student perception, hardware

\section{PENDAHULUAN}

Teknologi Informasi dan Komunikasi (TIK), atau dalam bahasa Inggris dikenal dengan istilah ICT (Information and Communication Technologies) adalah payung besar terminologi yang mencakup seluruh peralatan teknis untuk memproses dan menyampaikan informasi. Perkembangan TIK sudah sedemikian luas. Hampir seluruh instansi atau perusahaan memanfaatkan TIK sebagai pendukung dalam manajemen/pengelolaan instansi atau perusahaan. Misalnya dalam bidang perekonomian, dapat dilakukan transfer uang antar bank, transaksi jual-beli lewat internet, dan lain-lain. Dalam bidang politik, dapat dilakukan quick count (hitung cepat pemilu) di mana data perolehan suara dikirim melalui SMS 
gateway dan data diolah dengan bantuan database. Bidang pendidikan pun tidak luput dari perkembangan TIK tersebut.

Peraturan Menteri Riset, Teknologi Dan Pendidikan Tinggi Republik Indonesia, Nomor 44 Tahun 2015 tentang Standar Nasional Pendidikan Tinggi menyatakan Standar Nasional Pendidikan Tinggi adalah satuan standar yang meliputi Standar Nasional Pendidikan, Standar Nasional Penelitian dan Standar Nasional Pengabdian kepada Masyarakat. Standar Nasional Pendidikan Tinggi bertujuan untuk menjamin tercapainya tujuan pendidikan tinggi yang berperan strategis dalam mencerdaskan kehidupan bangsa, memajukan ilmu pengetahuan dan teknologi dengan menerapkan nilai humaniora serta pembudayaan dan pemberdayaan bangsa Indonesia yang berkelanjutan, menjamin agar pembelajaran pada program studi penelitian dan pengabdian masyarakat sesuai dengan kriteria yang ditetapkan dan mendorong agar perguruan tinggi mencapai mutu pembelajaran, penelitian dan pengabdian masyarakat melampaui kriteria yang ditetapkan dalam Standar Nasional Pendidikan Tinggi secara berkelanjutan.

HTML merupakan bahasa pemrograman yang digunakan untuk membuat aplikasi berbasis web. Bahasa pemrograman ini ditulis dalam berkas format ASCII, supaya dapat menghasilkan tampilan wujud yang terintegrasi Wahana Komputer (2015:2). Menurut Purbadian (2015:6) html mempunyai kepanjangan dari Hyper Text Markup yang merupakan pondasi awal akan terciptanya suatu aplikasi web, karena html memiliki fungsi untuk membangun kerangka ataupun format web yang digunakan untuk menampilkan suatu informasi ke dalam halaman web atau browser, html merupakan pula pengembangan dari pemformatan dokumen teks yaitu Standard Generalized Markup Languange (SGML).

Menurut Purbadian (2015:29), PHP yang mempunyai kepanjangan dari Hypertext Preprocessor merupakan bahasa pemrograman skrip yang ditempatkan disisi server, sehingga PHP disebut juga sebagai bahasa server side scripting artinya bahwa dalam menjalankan PHP selalu membutuhkan webserver dan untuk melihat hasilnya menggunakan webbrowse". Wahana Komputer (2012:76) PHP merupakan bahasa pemrograman berbasis web yang memiliki kemampuan untuk memproses dan mengolah data secara dinamis, PHP dapat dikatakan sebagai sebuah serverside embedde script languange, artinya sintak-sintak dan perintah program yang anda pada halaman HTML biasa. Dengan menggunakan PHP sebagai media pembelajaran, maka proses pembelajaran dapat menjadi lebih menarik karena media pembelajaran ini memiliki beberapa kelebihan dibandingkan media pembelajaran lain. Media pembelajaran dengan PHP dapat digunakan kapan saja dan di mana saja serta dapat melalui sistem operasi apa saja sebab berbasis web.

Sehingga pelajar dapat lebih mudah untuk mendapatkan materi pembelajaran serta video-video yang berhubungan dengan materi. Media pembelajaran dengan PHP juga memiliki kemampuan untuk mengolah keluaran gambar, video, animasi dan berbagai file yang membuat pelajar tidak bosan. Mahasiswa Program Studi 
Pendidikan Teknik Informatika dan Komputer Jurusan Pendidikan Teknik Elektro Fakultas Teknik Universitas Negeri Makassar sebagai pelajar dalam proses pembelajaran mata kuliah Perangkat Keras senantiasa mengharapkan peningkatan kualitas penyajian materi sehingga dapat meningkatkan motivasi dan kreatifitas dalam mencapai tujuan pembelajaran. Salah satu permasalahan yang ditemukan dalam pembelajaran mata kuliah Perangkat Keras adalah mahasiswa tidak dapat mengetahui fungsi dan memahami dengan baik cara kerja perangkat keras komputer apabila hanya dijelaskan secara visual. Akibatnya, proses pembelajaran dalam kelas menjadi kurang efektif. Berdasarkan hal tersebut penulis berinisiatif untuk melakukan perancangan perangkat lunak bantu pembelajaran mata kuliah perangkat keras berbasis web.

\section{METODE PENELITIAN}

Penelitian ini merupakan penelitian pengembangan perangkat lunak yang bertujuan untuk mengembangkan perangkat lunak bantu pembelajaran mata kuliah Perangkat Keras berbasis Web pada program studi Pendidikan Teknik Informatika dan Komputer, Jurusan Pendidikan Teknik Elektro Fakultas Teknik Universitas Negeri Makassar. Penelitian ini dilaksanakan di Program Studi Pendidikan Teknik Informatika dan Komputer Jurusan Pendidikan Teknik Elektro Fakultas Teknik Universitas Negeri Makassar. Objek penelitian ini adalah mahasiswa angkatan 2012 Program Studi Pendidikan Teknik Informatika dan Komputer Jurusan Pendidikan Teknik Elektro Fakultas Teknik Universitas Negeri Makassar yang memprogramkan mata kuliah Perangkat Keras pada semester genap tahun akademik 2012-2013 yang jumlahnya 37 orang.

Prosedur Perancangan

1. Perancangan

Kegiatan penelitian ini diawali dengan pengumpulan bahan ajar mata kuliah perangkat keras dan literatur yang berkaitan dengan PHP sebagai bahan dasar dari pembuatan media pembelajaran ini. Kemudian melakukan perancangan perangkat lunak dan database.

\section{a. Perancangan Database}

Perancangan database meliputi perancangan input output (DFD konteks, DFD model, ERD dan Usecase Diagram), dan kamus data

1. Perancangan Input Output

a) Data Flow Diagram (DFD) Konteks

Data Flow Diagram (DFD) disebut juga dengan Diagram Arus Data (DAD). DFD adalah suatu model logika data atau proses yang dibuat untuk menggambarkan dari mana asal data, dan ke mana tujuan data yang akan keluar dari sistem, di mana data disimpan, proses apa yang menghasilkan data tersebut, interaksi antara data yang tersimpan, dan proses yang dikenakan pada data tersebut (Iswandy, 2015). 


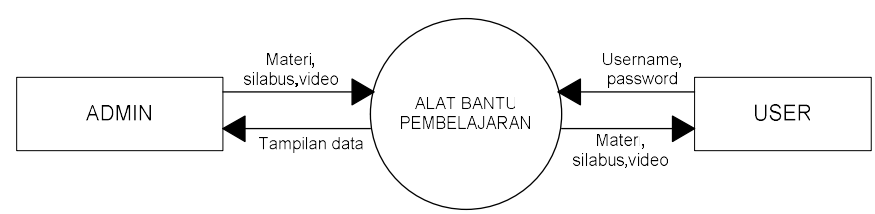

Gambar 1. Data Flow Diagram (DFD) konteks perangkat lunak bantu pembelajaran mata kuliah perangkat keras

b) Data Flow Diagram (DFD) Model

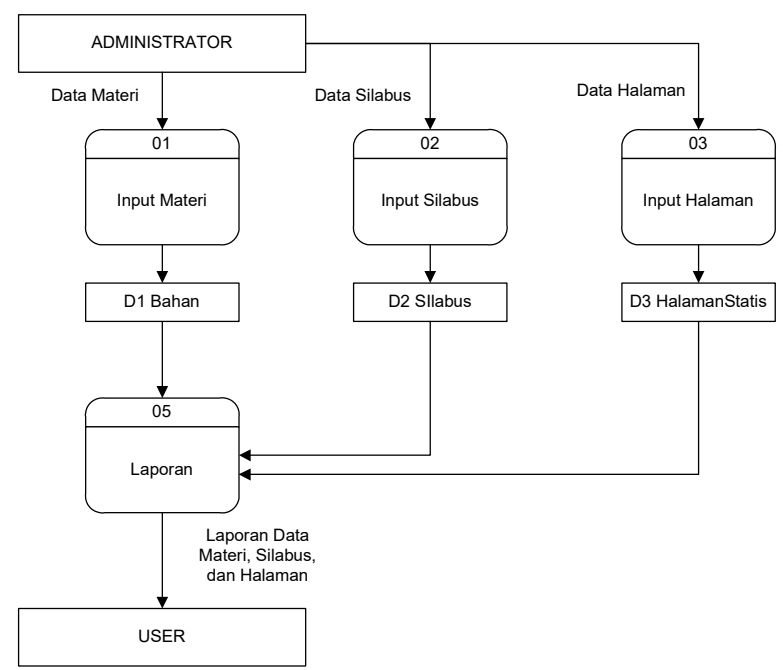

Gambar 2. Data Flow Diagram (DFD) model perangkat lunak bantu pembelajaran mata kuliah perangkat keras

c) Entity Relationship Diagram

ERD berguna untuk memodelkan sistem yang nantinya basis datanya akan dikembangkan. Model ini juga membantu perancang atau analisis sistem pada saat melakukan perancangan basis data yang menunjukkan hubungan antar data (Sutanta, 2011) 


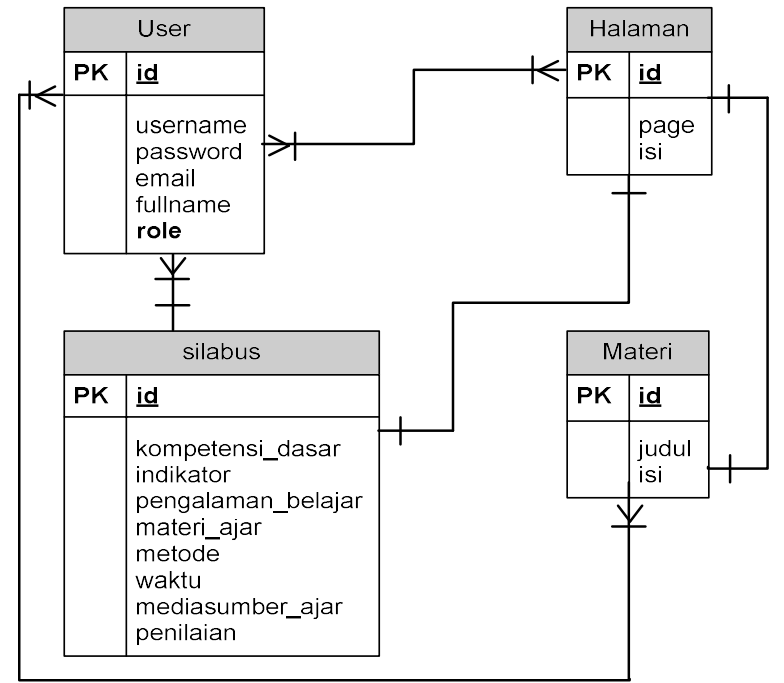

Gambar 3. Entity Relationship Diagram (ERD) Perangkat Lunak Bantu Pembelajaran Mata Kuliah Perangkat Keras

\section{d) Flowchart Halaman Utama}

Chandra \& Widiyanto (2014) menyebutkan bahwa flowchart merupakan bagan (chart) yang menunjukkan alir (flow) di dalam program atau prosedur sistem secara logika.

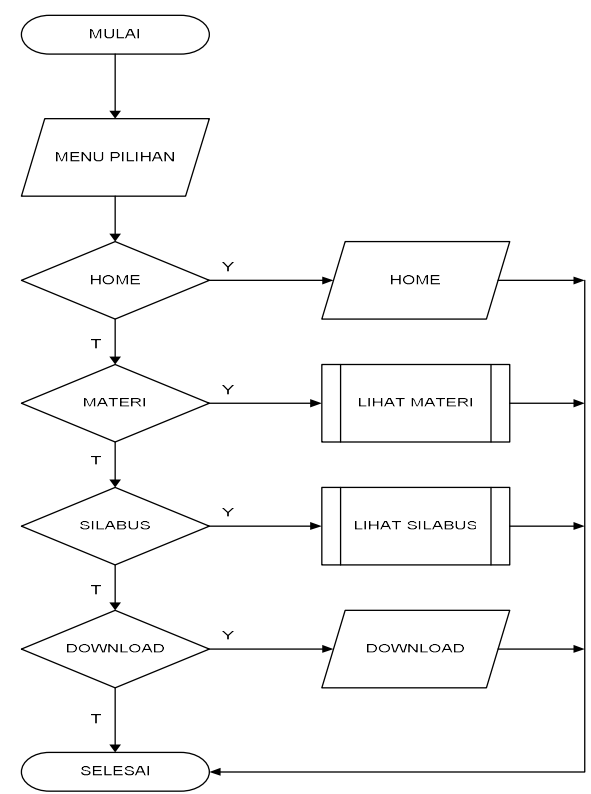

Gambar 4. Flowchart Halaman Utama 
e) Use Case Diagram Admin

Menurut Artina (2006) Use case merupakan teknik menangkap kebutuhankebutuhan fungsional dari sistem baru atau sistem yang diubah. Setiap use case terdiri dari satu atau lebih skenario yang menerangkan bagaimana sistem berinteraksi dengan pengguna atau sistem yang lain untuk mencapai suatu sasaran bisnis tertentu.

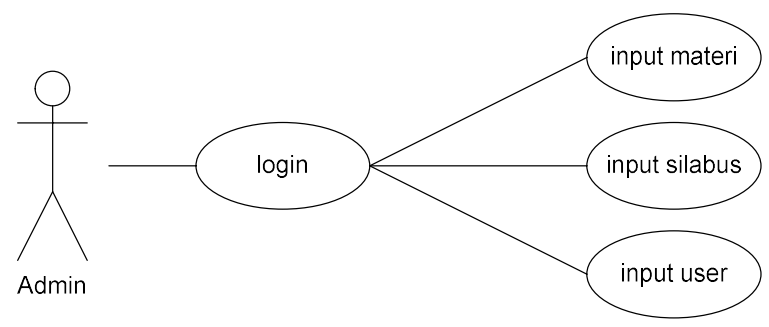

Gambar 5. Use Case Diagram Admin Perangkat Lunak Bantu Pembelajaran Mata Kuliah Perangkat Keras

f) Use Case Diagram User

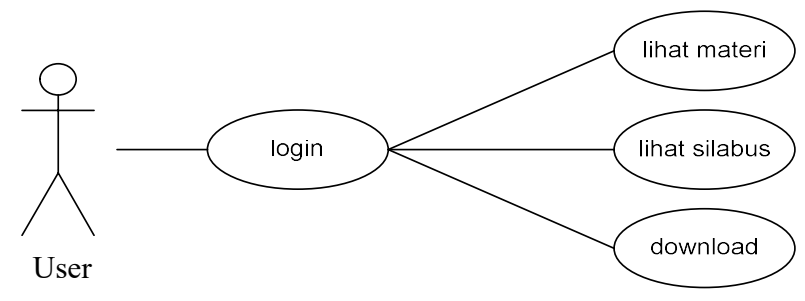

Gambar 6. Use Case Diagram User Perangkat Lunak Bantu Pembelajaran Mata Kuliah Perangkat Keras

\section{b. Perancangan Perangkat Lunak}

Perangkat Lunak ini terdiri dari dua kategori yaitu halaman user dan halaman khusus administrator.

1) Halaman User 


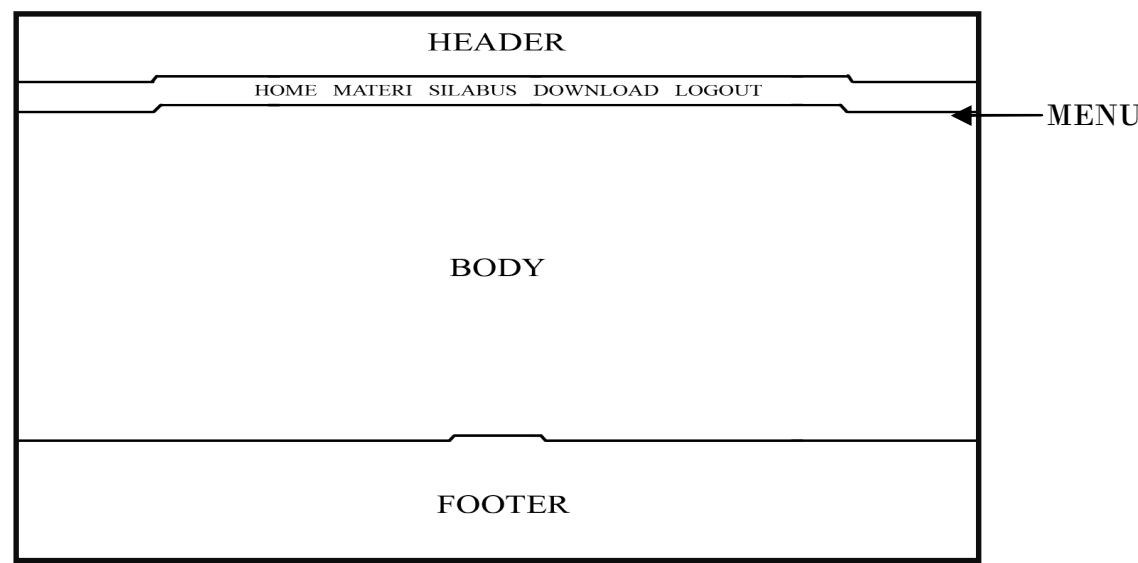

Gambar 7. Rancangan halaman user

Keterangan :

HEADER

MENU

HOME

MATERI

SILABUS : Halaman ini berisikan deskripsi mengenai mata kuliah Perangkat Keras. Modul yang mendukung fungsi ini adalah silabus.php

DOWNLOAD : Halaman ini adalah halaman yang akan terlihat apabila user telah login. Halaman ini berisikan e-book, beberapa tutorial dan video-video mengenai Perangkat Keras yang dapat didownload. Modul yang mendukung fungsi ini adalah download.php

LOGOUT : Menu untuk keluar dari halaman user. Modul yang mendukung fungsi ini adalah logout.php

FOOTER : Tulisan tentang keterangan dan tahun pembuatan perangkat lunak. 
2) Halaman Administrator (Panel Admin)

Halaman Administrator merupakan control panel dari perangkat lunak ini. Cara untuk mengakses halaman ini yaitu dengan mengklik menu Panel Admin pada halaman user. Halaman administrator terdiri dari beberapa halaman yaitu : form login, halaman home, atur materi, atur silabus, atur halaman statis, atur user, dan logout. Rancangan utama halaman administrator dapat dilihat di halaman berikutnya.

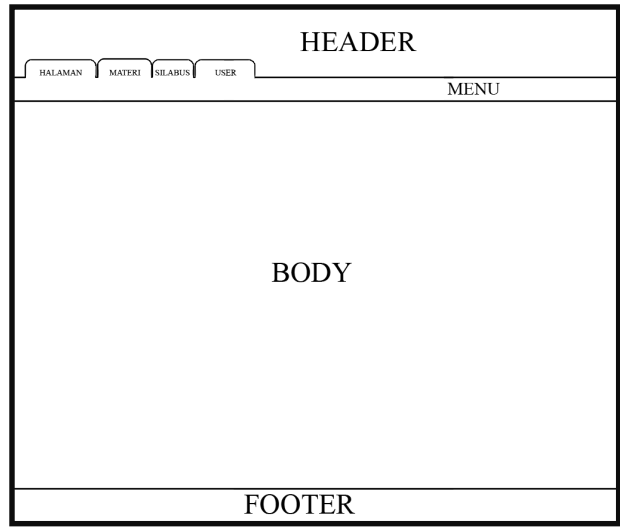

$$
\text { LOGOUT }
$$

Gambar 8. Rancangan halaman administrator

Keterangan :

FORM : Halaman awal ketika kita mengakses halaman administrator LOGIN ini. Modul yang mendukung fungsi ini adalah login.php

HEADER : Merupakan kop halaman admin.

MENU : Berisikan menu home, atur materi, atur silabus, atur halaman statis, atur user, dan logout.

HOME : Halaman yang memperlihatkan semua menu pada halaman admin ini. Modul yang mendukung fungsi ini adalah index.php

ATUR : Merupakan halaman pengaturan materi pembelajaran. Modul MATERI yang mendukung fungsi ini adalah aturmateri.php, aturmateri_input.php,aturmateri_edit.php,aturmateri_update.php, aturmateri_upload.php dan aturmateri_delete.php

ATUR : Merupakan halaman pengaturan silabus. Modul yang SILABUS mendukung fungsi ini adalah silabus.php, silabus_input.php, silabus_edit.php, silabus_update.php, silabus_upload.php dan silabus_delete.php

ATUR : Halaman untuk mengatur tampilan halaman statis yang ada HALAMAN yaitu home, silabus dan download. Modul yang mendukung STATIS fungsi ini adalah halstatis.php , halstatis_edit.php, 
halstatis_input.php, halstatis_update.php, halstatis_upload.php, halstatis_delete.php

ATUR : Pada halaman ini admin dapat mengubah data username dan USER password serta menambah atau menghapus user. Modul yang mendukung fungsi ini adalah user.php, user_input.php, user_edit.php, user_update.php, user_upload.php, user_delete.php

LOGOUT : Menu untuk keluar dari halaman admin. Modul yang mendukung fungsi ini adalah logout.php

2. Pengkodean (Coding)

Desain media pembelajaran perangkat keras berbasis web ini selanjutnya dituliskan dalam bentuk kode-kode pemrograman menggunakan bahasa PHP (Perl Hypertext Preprocessor) dan database MySQL.

3. Validasi Desain

Validasi desain merupakan proses kegiatan untuk menilai apakah rancangan produk dari media tersebut sudah layak untuk digunakan sebagai suatu media pembelajaran.

4. Pengujian

Perangkat lunak yang telah dibuat diuji menggunakan pengujian black box. Pengujian ini bertujuan untuk mengetahui apakah sistem dari perangkat lunak telah memenuhi kriteria untuk dapat digunakan sebagai media pembelajaran.

\section{Teknik Pengumpulan Data}

Proses pengumpulan data pada penelitian ini dilakukan dengan mempersiapkan instumen penelitian dan mengumpulkan data seperti silabus, RPP dan materi yang akan ditambahkan pada media yang akan dibuat. Pembuatan media pembelajaran mata kuliah Perangkat Keras dengan menggunakan PHP (Perl Hypertext Preprocessor) pada mahasiswa Program Studi Pendidikan Teknik Informatika dan Komputer Jurusan Pendidikan Teknik Elektro Fakultas Teknik Universitas Negeri Makassar kemudian dapat diterapkan pada proses perkuliahan. 6. Teknik Analisis Data

Data penelitian yang terkumpul dianalisis dengan menggunakan teknik statistik deskriptif. Analisis ini meliputi rata-rata, median, modus, simpangan baku, skor minimum, dan skor maksimum. Distribusi data diklasifikasikan atas empat kategori, yaitu : sangat tinggi, tinggi, rendah, dan sangat rendah.

\section{HASIL DAN PEMBAHASAN}

\section{Ringkasan Format Manuskrip}

1. Media pembelajaran

Perancangan media pembelajaran mata kuliah perangkat keras berbasis PHP (Perl Hypertext Preprocessor) diawali dengan mengumpulkan data seperti 
silabus, bahan ajar mata kuliah perangkat keras dan literatur yang berkaitan dengan program PHP. Hasil validasi dan uji coba media kemudian direvisi kembali sebelum dilakukan desimination atau penyebaran. Beberapa tampilan gambar utama dapat dilihat pada halaman berikutnya.

a. Halaman Utama (Home)

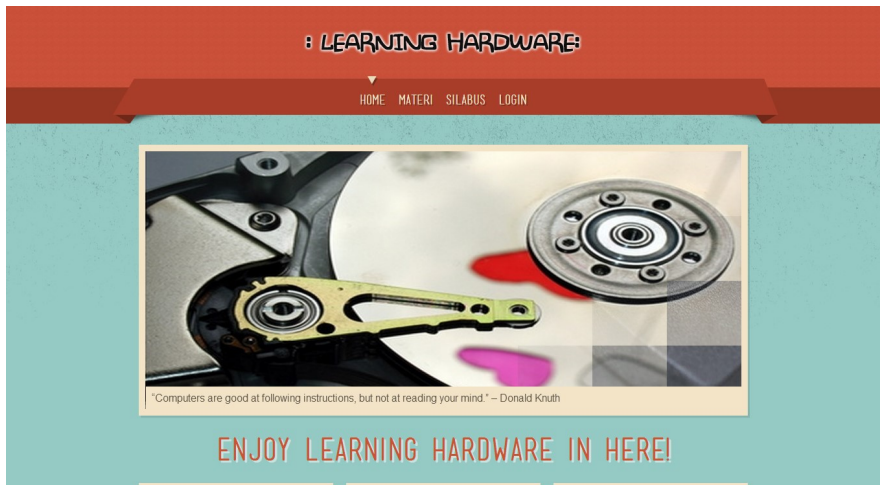

Gambar 9. Halaman utama media pembelajaran perangkat keras berbasis PHP

Halaman utama merupakan halaman yang bisa diakses oleh semua pengunjung. Halaman utama terdiri dari beberapa menu, yaitu : halaman home, materi, silabus dan login. Menu yang ada di halaman utama ini akan berbeda saat pengunjung melakukan login. Jika login sebagai user biasa akan ada tambahan menu download, sedangkan jika login sebagai administrator selain menu download akan ada menu panel admin.

\section{HOME MATERI SILABUS DOWNLOAD LOGOUT}

Gambar 10. Menu untuk user biasa

\section{HOME MATERI SILABUS PANEL ADMIN DOWNLOAD LOGOUT}

Gambar 11. Menu untuk administrator

b. Halaman Login

Halaman login adalah halaman di mana user dan admin memasukkan username dan password agar dapat mengakses semua fitur yang ada pada media pembelajaran. 


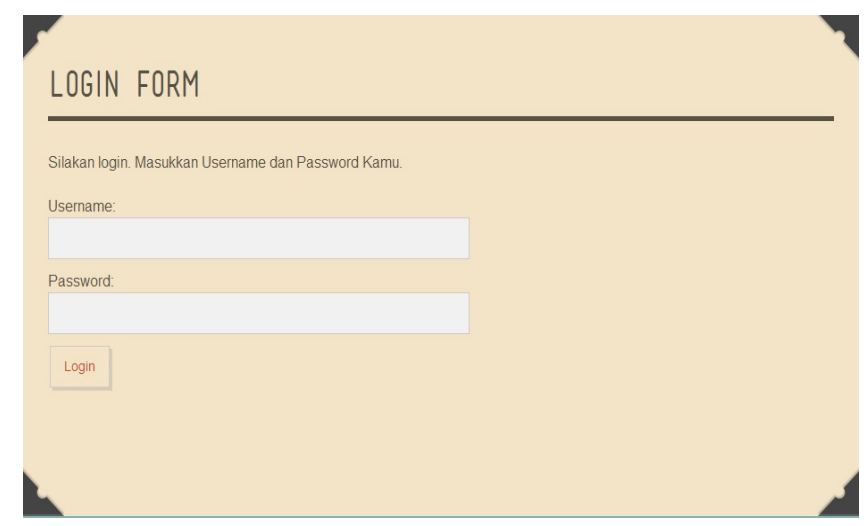

Gambar 12. Halaman login user

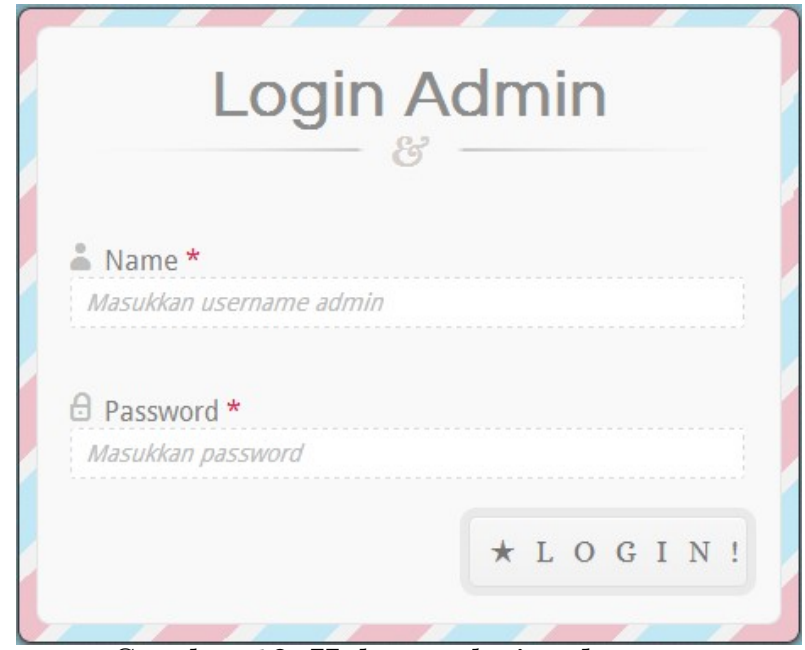

Gambar 13. Halaman login admin

\section{Validasi Expert (Ahli)}

Validasi desain media pembelajaran berbasis PHP (Perl Hypertext Preprocessor) merupaka proses kegiatan untuk menilai kelayakan media sebelum digunakan sebagai suatu media pembelajaran. Validasi dilakukan oleh ahli (expert) validasi media pembelajaran diawali dengan mendemonstrasikan secara langsung dan memberikan lembar penilaian kepada dua orang ahli (expert) media. Hasil penilaian kedua ahli media dapat dilihat pada lampiran $\mathrm{C}$.

3. Uji Coba Instrumen

Setelah dilakukan pengujian validitas dan reliabilitas maka diperoleh hasil sebagai berikut. Hasil pengujian validasi menunjukkan bahwa dari 30 butir item instrumen terdapat 2 item yang tidak valid (gugur) yaitu item dengan nomor 1 
dan 28. Pengukuran reliabilitas instrumen diperoleh dengan bantuan software Microsoft Excel dan IBM SPSS 20 dengan fasilitas Cronbach Alpha (a). Suatu variabel dikatakan realibel jika memberikan nilai Cronbach Alpha $>0.60$. Nilai koefisien yang diperoleh dari pengujian instrumen ini adalah 0.886 . Karena nilai reliabilitas yang dihasilkan lebih besar dari 0.60 maka variabel yang digunakan dapat dikatakan reliabel. Dengan uji validitas dan reabilitas maka instrumen dinyatakan layak digunakan sebagai instrumen penelitian .

4. Hasil Analisis Deskriptif

Hasil analisis deskriptif disajikan pada pembahasan ini untuk memberikan gambaran tentang persepsi mahasiswa kelas 04 angkatan 2012 PTIK JPTE FT UNM terhadap menerapan media pembelajaran berbasis PHP (Perl Hypertext Preprocessor) mata kuliah Perangkat keras.

Tabel 1. Hasil analisis statistik deskriptif tentang persepsi mahasiswa terhadap media pembelajaran berbasis PHP (Perl Hypertext Preprocessor) pada mata kuliah

Perangkat keras.

\begin{tabular}{|l|r|}
\hline \multicolumn{1}{|c|}{ Statistik } & Nilai \\
\hline Mean & 86.92 \\
\hline Standard Error & 1.17 \\
\hline Median & 85 \\
\hline Mode & 84 \\
\hline Standard Deviation & 7.13 \\
\hline Sample Variance & 50.80 \\
\hline Kurtosis & 0.01 \\
\hline Skewness & 0.54 \\
\hline Range & 31 \\
\hline Minimum & 73 \\
\hline Maximum & 104 \\
\hline Sum & 3216 \\
\hline Count & 37 \\
\hline
\end{tabular}

Berdasarkan Tabel 1 dapat dilihat bahwa jumlah sampel (count) 37, nilai rata-rata (mean) sebesar 86.92 , standard error 1.17, titik tengah atau nilai tengah (median) sebesar 85, nilai yang paling banyak muncul (mode) 84, standar deviasi dan tingkat sebaran data (sample varians) 7.13 dan 50.80, ukuran kepuncakan (kurtosis) 0.01, ukuran keponcongan (skewness) 0.54, range 31, data minimum 73 data maksimum 104 dan sum 3216. 
Tabel 2. Distribusi frekuensi, kategori hasil analisis statistik deskriptif tentang persepsi mahasiswa terhadap media pembelajaran berbasis PHP (Perl Hypertext

Preprocessor) pada mata kuliah Perangkat keras.

\begin{tabular}{|c|c|c|c|c|c|c|}
\hline Kategori & \multicolumn{3}{|c|}{ Interval kelas } & F absolut & $\%$ relatif & $\%$ kumulatif \\
\hline Sangat Baik & 3.51 & \multicolumn{2}{|c|}{ ke atas } & 3 & 8.11 & 8.11 \\
\hline Baik & 2.51 & s.d & 3.50 & 34 & 91.89 & 100.00 \\
\hline Kurang & 1.51 & s.d & 2.50 & 0 & 0.00 & \\
\hline Sangat Kurang & \multicolumn{2}{|c|}{ di bawah } & 1.50 & 0 & 0.00 & \\
\hline \multicolumn{4}{|c|}{ Jumlah } & 37 & 100.00 & \\
\hline
\end{tabular}

Berdasarkan Tabel 2, dari jumlah 37 orang mahasiswa terdapat 3 orang atau $8.11 \%$ mahasiswa yang menganggap media pembelajaran Perangkat Lunak berbasis PHP sangat baik, dan 34 orang atau 91.89\% yang menilai dengan kategori baik. Data pada Tabel 4.2 juga dapat digambarkan seperti gambar histogram berikut :

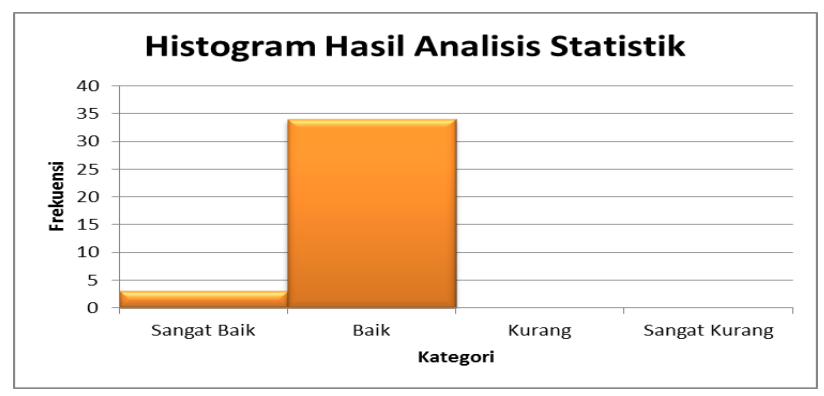

Gambar 14. Histogram hasil analisis statistik deskriptif tentang persepsi mahasiswa terhadap media pembelajaran berbasis PHP (Perl Hypertext

Preprocessor) pada mata kuliah Perangkat keras.

Tabel 2 dan Gambar 14 di atas menunjukkan persepsi mahasiswa terhadap media pembelajaran berbasis PHP (Perl Hypertext Preprocessor) pada mata kuliah Perangkat keras yang dikelompokkan menjadi 4 kategori dasar yaitu sangat baik (interval > 3.51), baik (interval 2.51 s.d 3.5), kurang (1.51 s.d 2.50) dan kategori sangat kurang (interval $<1,51$ ).

Media pembelajaran berbasis PHP (Perl Hypertext Preprocessor) dalam penelitian ini berupa media interaktif mata kuliah Perangkat keras. Pada media pembelajaran ini terdapat konten multimedia seperti visualisasi tulisan, gambar, animasi, dan video.

Berdasarkan hasil uji coba dapat dilihat bahwa secara umum media pembelajaran berbasis PHP (Perl Hypertext Preprocessor) ini berada dalam kategori 
baik. Berdasarkan angket uji coba, penilaian mahasiswa dari segi tampilan media sudah baik. Berdasarkan dari hasil analisis statistik deskriptif, nilai rata-rata (mean) sebesar 86.92. hal ini menandakan bahwa tingkat rata-rata pengskoran pada angket yang telah disebar dan sesuai pilihan mahasiswa berada pada kategori baik. Standard error 1.17, titik tengah atau nilai tengah (median) sebesar 85, nilai yang paling banyak muncul (mode) 84, standar deviasi dan tingkat sebaran data (sample varians) 7.13 dan 50.80. Dari nilai tersebut dapat dikatakan bahwa tingkat sebaran data adalah berdistribusi normal. Ukuran kepuncakan (kurtosis) 0.01, ukuran keponcongan (skewness) 0.54. Dalam buku SPSS 17 dikatakan bahwa ketika nilai kurtosis dan skewness berada pada interval -2 s.d 2 maka data tersebut berdistribusi normal.

Distribusi frekuensi menunjukkan pengkategorian persepsi mahasiswa dalam 4 kategori dasar yaitu sangat baik (interval > 3.51), baik (interval 2.51 s.d 3.5), kurang (1.51 s.d 2.50) dan kategori sangat kurang (interval < 1,51). Dari hasil tersebut dapat dikatakan bahwa mahasiswa memiliki pandangan positif tentang media pembelajaran berbasis PHP (Perl Hypertext Preprocessor) dengan pilihan 34 orang berada pada kategori baik dan 3 orang berada pada kategori sangat baik.

\section{SIMPULAN}

Berdasarkan hasil dapat disimpulkan bahwa perancangan media pembelajaran dilakukan dengan mengumpulkan bahan pembelajaran kemudian merancang perangkat lunak serta database yang diperlukan. Media pembelajaran yang telah dibuat selanjutnya divalidasi oleh dua orang ahli media sebelum dilakukan desimination atau penyebaran. Dari hasil analisis deskriptif dapat diketahui bahwa mahasiswa memiliki pandangan positif terhadap media pembelajaran PHP dengan melihat interval nilai yang berada pada kategori baik sebesar $91.89 \%$. Ini berarti media yang dihasilkan dapat digunakan sebagai media pembelajaran pada mata kuliah Perangkat Keras.

\section{SARAN DAN REKOMENDASI}

Bagi dosen, mahasiswa dan peneliti lain, diharapkan dapat menggunakan media tersebut serta dapat mengembangkan media pembelajaran menjadi media pembelajaran interkatif dan menarik.

\section{DAFTAR PUSTAKA}

Artina, N. (2006). Penerapan Analisis Kebutuhan Metode Use Case pada Metode Pengembangan Terstruktur. Jurnal Ilmiah STMIK GI MDP Palembang.

Chandra, B. F., \& Widiyanto, P. E. (2014). Rancang Bangun Sistem Informasi Geografis Rute Angkutan Kota di Palembang (Seminar Perkembangan dan Hasil Penelitian Ilmu Komputer). SPHP-ILKOM. 
Iswandy, E. (2015). Sistem Penunjang Keputusan untuk Menentukan Penerimaan Dana Santunan Sosial Anak Nagari dan Penyalurannya Bagi Mahasiswa dan Pelajar Kurang Mampu Di Kenagarian Barung - Barung Balantai Timur. Jurnal TEKNOIF.

Peraturan MenteriRiset, Teknologi Dan Perguruan Tinggi Republik Indonesia Nomor 44 Tahun 2015 Tentang Standar Nasiona PPendidikan.

Purbadian Yenda. 2015. Aplikasi Penjualan Web Base Dengan Php Untuk Panduan Skripsi. Cirebon. Asfa Solution

Sutanta, E. (2011). Basis Data dalam Tinjauan Konseptual. Yogyakarta: Andi.

Wahana Komputer. 2012. Membangun Web Interaktif Dengan Adobe Dreamweaver Css.5, Php \& Mysql. Yogyakarta. Andi.

Wahana Komputer. 2015. Web Master Series: Menguasai Html. Yogyakarta. Andi. 